\title{
Coordination of mammary metabolism and blood flow after refeeding in rats
}

\author{
K. W. Stewart, ${ }^{*}$ G. J. S. Cooper, † and S. R. Davisł \\ *School of Science and Primary Industries, Waikato Institute of Technology, Hamilton, New Zealand \\ †School of Biological Sciences, University of Auckland, New Zealand \\ $\ddagger$ Vialactia Biosciences, Hamilton, New Zealand
}

\begin{abstract}
The production of milk is closely linked to nutritional state in many mammalian species, but the mechanisms by which changes in nutritional state are signaled to the mammary glands are poorly understood. Simultaneous measurements of mammary blood flow and glucose arterio-venous difference were made across the inguinal mammary glands of anesthetized, lactating rats. Blood flow to the mammary glands of previously fed rats was $0.48 \mathrm{~mL} / \mathrm{min}$ per gram of mammary tissue. Glucose supply was $1.7 \mu \mathrm{mol} / \mathrm{min}$ per gram and $28 \%$ was extracted by the mammary glands. After food deprivation for $18 \mathrm{~h}$, mammary blood flow decreased $48 \%$, glucose arterio-venous difference decreased $72 \%$, and hematocrit increased $7 \%$, resulting in a $60 \%$ decrease in glucose supply and an $88 \%$ decrease in glucose uptake. After $1 \mathrm{~h}$ of refeeding, glucose supply had returned to a similar level to that of normally fed animals, but glucose uptake was $60 \%$ higher than in the normally fed state. Mammary glucose uptake was not closely linked to either blood flow or glucose supply, suggesting that substrate supply was not the primary determinant of mammary metabolism. Denervation experiments showed that the mammary metabolic response to altered nutritional state was also unlikely to be closely controlled by neural pathways. Severance of the cutaneous branch of the posterior division of the femoral nerve innervating the inguinal mammary glands did not reduce the high glucose uptake by mammary glands of either fed or refed rats, nor did denervation change the low glucose uptake by mammary glands of food-deprived rats. Denervation reduced blood flow in the associated mammary gland, however, indicating that neural pathways may play a role in supporting mammary blood flow when food is available. In in vitro experiments, the rate of glucose uptake was $35 \%$ lower in mammary acini from food-deprived rats than in fed rats $2.5 \mathrm{~h}$ after tissue removal, indicating some
\end{abstract}

Received August 10, 2008.

Accepted November 25, 2008

${ }^{1}$ Corresponding author: Kevin.Stewart@wintec.ac.nz persistence of the food deprivation-induced suppression of mammary metabolism. Administration of insulin increased glucose uptake in acini from both fed and fooddeprived rats, indicating that insulin may be involved in signaling the mammary gland of the restoration of nutrient supply when food-deprived rats are refed. The effects of administration of a gut extract in vivo and in vitro are discussed.

Key words: mammary blood flow, mammary glucose uptake, refeeding, mammary metabolism

\section{INTRODUCTION}

Milk production has been demonstrated to be acutely sensitive to availability of food in ruminants (Faulkner and Peaker, 1987) and rodents (Williamson and Robinson, 1977). For example, when food was removed from lactating rats, glucose extraction from mammary blood fell rapidly and substantially [60\% after $6 \mathrm{~h}$ (Jones and Williamson, 1984) and $92 \%$ after $18 \mathrm{~h}$ (Page and Kuhn, 1986)]. In addition, mammary synthesis of both fatty acids and lactose fell to low levels after food withdrawal in lactating rats (Bussmann et al., 1984).

Mammary metabolism was rapidly restored to fed levels when food was reoffered to food-deprived rats. Mammary glucose extraction was largely restored in conscious lactating rats after only 15 min of refeeding and fully restored after $1 \mathrm{~h}$ (Page and Kuhn, 1986). In other studies, refeeding increased the uptake of 2-deoxy-D-glucose (2DG) by mammary glands to the fed level after $1 \mathrm{~h}$ (Threadgold and Kuhn, 1984) and restored glucose extraction to fed levels after $2 \mathrm{~h}$ (Jones and Williamson, 1984).

The pathways by which nutritional status is signaled to the mammary glands and the metabolic sites targeted by these pathways have not been clearly identified. This investigation examines aspects of the signaling pathways that lead to this rapid switching on of mammary metabolism on refeeding of food-deprived rats.

Insulin has been implicated in the mammary response to refeeding as it has been shown to influence mammary responses to nutritional changes. If insulin secretion was prevented, mammary lipogenesis did 
not show the usual recovery when food-deprived rats were refed (Mercer and Williamson, 1986). Conversely, insulin administration to food-deprived rats increased lipogenesis (Jones et al., 1984) and glucose extraction (Page and Kuhn, 1986). Furthermore, in studies in which food-deprived rats were refed, the time course of the recovery in lipogenesis (Mercer and Williamson, 1986) and glucose extraction (Page and Kuhn, 1986) was paralleled by that of blood insulin concentration.

Some researchers have speculated that a gut hormone may be involved in the increase in mammary metabolism observed after refeeding of food-deprived rats (Carrick and Kuhn, 1978; Williamson, 1980). It was suggested that this hormone is released when food becomes available or is ingested; hence, signaling the mammary glands of the end of the starvation state and activating metabolism. Such a mechanism was supported by Page (1989), who reported that intraperitoneal administration of a crude gut extract increased glucose extraction from blood supplying the inguinal mammary glands of anesthetized lactating rats if the cutaneous branch of the posterior division of the femoral nerve innervating the inguinal mammary glands was severed and blood insulin concentration was increased.

These 3 studies suggest that the physiological pathway controlling the increase in mammary metabolism on refeeding may be mediated by the coordinated involvement of a gut hormone, insulin, and neural pathways. However, we believe some caution should be applied to the interpretation of these results as we consider that the methods used to assess in vivo mammary glucose uptake in previous studies had inherent inaccuracies.

To accurately measure net glucose uptake rates, simultaneous measurements of mammary blood flow (MBF) and glucose arterio-venous difference (AVD) must be made under steady-state conditions (Zierler, 1961). This has not been achieved simultaneously in any published studies using rats. Mammary blood flow has not been directly measured in rats but has been estimated using less-accurate single measurement techniques such as i.v. injection of radioactive compounds [e.g., ${ }^{3} \mathrm{H}_{2} \mathrm{O}$ (Chatwin et al., 1969) or ${ }^{86} \mathrm{RbCl}$ (Hanwell and Linzell, 1973)], microspheres (Jones and Williamson, 1984), or radiolabeled microspheres (Vina et al., 1987) and examination of their vascular distribution after a short period.

The methods employed for removal of mammary venous blood in previous studies was also likely to produce systematic errors. Blood was obtained either by puncturing the mammary vein and collecting blood by capillary action using a micro-hematocrit tube (Page and Kuhn, 1986; Page, 1989) or by aspiration using a syringe and 25-gauge needle introduced into the mammary vein (Hawkins and Williamson, 1972; Robinson and Williamson, 1977b; Vina et al., 1981, 1983). Further escape of blood was then prevented using pressure or by placing a piece of gauze over the hole in the vessel. Such procedures are likely to have altered MBF directly by obstructing venous drainage, and indirectly by inducing spasm of the mammary artery and vein (Mendelson and Scow, 1972; Clegg, 1988). Another potential problem with the removal of blood from the mammary vein using these methods is that mammary venous blood may be inadvertently contaminated by blood from veins distal to the mammary vein. Variation in blood flow produced by blood sampling procedures may explain the wide variation in reported results for glucose extraction by the inguinal mammary glands of fed rats at peak lactation [25\% (Hawkins and Williamson, 1972); 30\% (Robinson and Williamson, 1977a); 35\% (Jones and Williamson, 1984); and 60\% (Page and Kuhn, 1986)].

In the present study, a method was developed to make accurate measurements of glucose uptake in anesthetized rats to investigate the possible coordination of blood glucose and insulin levels with neural pathways and a factor from the gut in signaling the presence of food to the mammary glands. A rat mammary acini model was also used in vitro to assess cell performance after feed withdrawal and in response to hormonal stimulation.

\section{MATERIALS AND METHODS}

\section{General Methods}

This study was undertaken with the approval of the Ruakura Animal Ethics Committee (Hamilton, New Zealand). Lactating Sprague-Dawley rats between d 12 and 16 postpartum were anesthetized with Nembutal [45 mg/kg intraperitoneal (i.p.) injection followed by $0.2 \mathrm{mg} / \mathrm{kg}$ per min i.p. infusion] and positioned dorsally on a platform maintained at $37^{\circ} \mathrm{C}$. The rats were surgically prepared for measurement of blood flow to the left inguinal mammary glands. An incision was made through the skin on the inner surface of the left hind leg and the mammary tissue was lifted and separated from the underlying tissue to enable access to the iliac artery and vein. Under microscopy, all distal arteries apart from the inguinal mammary (superficial epigastric) artery were ligated. The iliac artery was separated from the associated vein, nerve, and other tissue to enable positioning of a perivascular flow probe $(1 \mathrm{~mm}$, Transonics Systems, Ithaca, NY). An acoustic coupling gel was applied to the probe as per manufacturer instructions and the probe carefully positioned to prevent disturbance of blood flow in the artery. Mammary blood flow was monitored continuously throughout each 
experiment via a flowmeter (model T108, Transonics Systems) and data recorded using a MacLab 8 data recorder and Chart software (ADInstruments, Sydney, New South Wales, Australia). The time from administration of anesthetic to first recording of MBF after surgery was approximately $30 \mathrm{~min}$.

In animals in which glucose extraction was measured, a catheter $(0.20 \mathrm{~mm}$ i.d., $0.50 \mathrm{~mm}$ o.d.) was inserted into the proximal saphenous vein on the medial surface of the left hind leg. The tip of the catheter was advanced to the point where the distal end of the superficial epigastric vein, which drains blood from the inguinal mammary glands, joins the saphenous vein. The catheter tip was carefully positioned under microscopy to ensure it did not obstruct mammary venous drainage. Catheter patency was maintained by the injection of $0.05 \mathrm{~mL}$ of saline every $5 \mathrm{~min}$. To ensure that only blood from the mammary vein was withdrawn, all other veins draining into the saphenous vein were ligated. To sample mammary venous blood, $0.1 \mathrm{~mL}$ of blood was slowly drawn into a syringe over $30 \mathrm{~s}$.

Arterial blood was sampled from another catheter inserted into the right (contralateral side to blood flow and sampling) saphenous artery. Blood was allowed to flow under hydrostatic pressure into each of 2 heparinized micro-hematocrit tubes (total volume $0.1 \mathrm{~mL}$ ) over $30 \mathrm{~s}$. Arterial and venous samples were taken simultaneously. Hematocrit was measured on the first arterial blood sample. The first blood samples were taken after 10 min of steady MBF recording (approximately $1 \mathrm{~h}$ after administration of anesthetic). Two further samples were taken at 10-min intervals and the results of the 3 measurements averaged.

In some rats, blood pressure was measured from the saphenous arterial blood sampling catheter by a Meritrans (Merit Medical, Salt Lake City, UT) pressure transducer, and recorded using a MacLab 8 data recorder; sampling rate was 100/s. Mean arterial pressure was determined by calculating the average of approximately 1,000 sequential blood pressure recordings.

In animals in which neural connections with the mammary glands were severed, the cutaneous branch from the posterior division of the femoral nerve (henceforth referred to as the mammary nerve) was dissected free from the mammary artery and vein. A ligature was placed around the nerve to facilitate its later sectioning without interfering with blood flow in the mammary artery.

When insulin was administered intravenously, $0.2 \mu \mathrm{g}$ ( $5 \mathrm{mU}$ ) of insulin (bovine, Sigma-Aldrich, St. Louis, $\mathrm{MO})$ in $0.1 \mathrm{~mL}$ of PBS was slowly injected via the venous blood-sampling catheter.

To study the effects of food deprivation in some animals, food was removed $18 \mathrm{~h}$ before experimentation.
Other animals were refed for $60 \mathrm{~min}$ following the 18-h food withdrawal. They were anesthetized at the end of this period. The mean weight $( \pm \mathrm{SEM})$ of rats was 360 $\pm 8 \mathrm{~g}$ (fed rats), $307 \pm 6 \mathrm{~g}$ (food-deprived rats), and $342 \pm 8$ g (refed rats).

Preparation of a gut extract was carried out using acid-ethanol extraction as described by Page (1989). Briefly, the stomach, duodenum, and distal 10-cm section of the ileum were removed from fed lactating rats and the lumen contents removed by flushing with cold PBS. The tissue was minced and stirred for $24 \mathrm{~h}$ in 0.1 $M \mathrm{HCl}$ in $75 \%$ ethanol at $4^{\circ} \mathrm{C}$. It was then centrifuged at $30,000 \times g$ for 30 min and the supernatant freeze-dried after extraction of the ethanol. The resulting powder was reconstituted in PBS and stored at $-20^{\circ} \mathrm{C}$.

\section{MBF over $4 h$}

Baseline measurements for $4 \mathrm{~h}$ were made in 8 fed, 8 starved, and 9 refed lactating rats to determine whether MBF was affected by anesthesia and nutritional state over this period. The first measurement was made 30 min after administration of anesthetic. Rats were left undisturbed for a further $3.5 \mathrm{~h}$. Average blood flow over 1 min was determined at 30 -min intervals.

\section{Glucose Supply and Uptake by Mammary Tissue}

In another group of rats, experiments examined the supply of glucose to the left inguinal mammary gland and the extraction of glucose by the glands. Simultaneous arterial and venous blood samples were taken from each of 7 rats in each nutritional state, and glucose AVD was determined. Hematocrit and MBF were measured 3 times (at 10-min intervals) in each rat, and the mean of the 3 measurements was used. The quantity of glucose supplied by the left mammary artery to the left inguinal mammary gland was calculated [plasma concentration $(\mathrm{mM}) \times$ mammary plasma flow $(\mathrm{mL} / \mathrm{min})]$. The percentage of glucose extracted from mammary arterial blood was then calculated using the glucose uptake measurement for each rat.

\section{Effect of Mammary Nerve Section}

The ipsilateral nerve was severed in rats in each of the fed, food-deprived, and refed nutritional states ( $\mathrm{n}=7$ in each state) and the contralateral nerve in food-deprived $(\mathrm{n}=3)$ and refed $(\mathrm{n}=3)$ rats. Blood samples were taken after three 10-min pre-denervation and two 10-min post-denervation intervals. Total volume removed was $1 \mathrm{~mL}$ per rat, or approximately $4 \%$ of blood volume (Diehl et al., 2001), with about half of the sampling volume replaced with saline when the cannulas were flushed after sampling. 


\section{Effect of Insulin and Gut Extract in the Mammary Gland of Food-Deprived Rats after Section of the Mammary Nerve}

The mammary nerve was severed after control MBF measurement and blood sampling. A further sample was taken $20 \mathrm{~min}$ later and $0.2 \mu \mathrm{g}$ of insulin administered (i.v.) either alone $(\mathrm{n}=6)$ or at the same time as gut extract $(\mathrm{n}=7 ; 10 \mathrm{mg}$ of protein $/ \mathrm{mL}$ in $1.5 \mathrm{~mL}$ i.p.). Subsequent samples were taken 10, 15, and $20 \mathrm{~min}$ after treatment.

\section{In Vitro Preparation of Mammary Acini}

Mammary tissue (2 g) was removed from anesthetized lactating rats, minced, and mixed for $75 \mathrm{~min}$ at $37^{\circ} \mathrm{C}$ in $30 \mathrm{~mL}$ of medium-199 containing Collagenase V (Sigma Aldrich, 1,000 units/mL). Oxygen (95\%) and $\mathrm{CO}_{2}(5 \%)$ was bubbled into the medium during digestion. This digestion procedure was a modification of previously published methods such as that of Katz et al. (1974) to isolate clusters of secretory cells (acini) from mammary tissue. Cells in acini preparations have been demonstrated to be more appropriate for this type of experiment than using isolated cells or tissue slices as the cells retain greater metabolic activity (Katz et al., 1974; Robinson and Williamson, 1977a). Acini were filtered through a $400-\mu \mathrm{m}$ screen. A centrifugal washing procedure was used to remove collagenase, blood cells, small groups of secretory cells, and tissue debris $(45 \times g$ for $3 \mathrm{~min}$ followed by resuspension in $10 \mathrm{~mL}$ of medium 3 times). Final volume was $15 \mathrm{~mL}$. Cell concentration was determined by counting crystal violet-stained nuclei in an aliquot after cell lysis by vortexing.

Aliquots of $0.5 \times 10^{6}$ cells in $0.7 \mathrm{~mL}$ of medium-199 containing HEPES $(25 \mathrm{mM})$ and glucose $(5 \mathrm{mM})$ were placed in 12 -well culture dishes at $37^{\circ} \mathrm{C}$. One microcurie of ${ }^{3} \mathrm{H}-2 \mathrm{DG}$ was added to each well and the dishes gently rocked for $60 \mathrm{~min}$. Dishes were then placed on ice to inhibit further uptake of glucose (Threadgold et al., 1982). Acini were transferred to 1.5-mL Eppendorf tubes and washed twice with $0^{\circ} \mathrm{C}$ PBS by centrifuging at 2,000 $\times g$ for $1 \mathrm{~min}$ and decanting. Cells were lysed with $0.1 \mathrm{~mL}$ of $5 \%$ TCA followed by the addition of $1 \mathrm{~mL}$ of scintillation fluid and scintillation counting (Wallac 1400 DSA, Wallac Oy, Turku, Finland).

Insulin $(0.1 \mu \mathrm{g}$ to produce a final concentration of 25 n $M$, human, Actrapid, NovoNordisk, Bagsvaerd, Denmark) or bovine insulin ( $1 \mu \mathrm{g}$ to produce a final concentration of $227 \mathrm{n} M$, bovine, Sigma-Aldrich) were added to some wells before addition of ${ }^{3} \mathrm{H}-2 \mathrm{DG}$. This provided respective insulin concentrations that were approximately 100 and 1,000 times greater than the concentration in plasma of lactating rats. Gut extract (7 $\mu \mathrm{g}$ of protein) was also added to some wells.

\section{RESULTS}

\section{MBF over $4 h$}

Average blood flow in the left inguinal mammary artery in fed lactating rats 30 min after administration of anesthetic was $2.61 \pm 0.33 \mathrm{~mL} / \mathrm{min}(\mathrm{n}=8$; Figure 1$)$. Statistical analysis using a linear mixed effects model (ANOVA, S-PLUS, Tibco Software Inc., Palo Alto, $\mathrm{CA})$ with $\mathrm{MBF}$, time, and nutritional state as fixed effects and animal as a random effect showed a significant effect of nutritional state $(P<0.001)$. Post hoc analysis using the Tukey Honestly Significant Difference test indicated that MBF over $4 \mathrm{~h}$ in food-deprived rats was significantly less than in fed $(P<0.001)$ and refed $(P<0.001)$ rats. Mammary blood flow remained relatively stable over the remainder of the 4-h period. Mammary blood flow in rats that had been refed for 60 min increased over the next $90 \mathrm{~min}$ from $1.87 \pm 0.30$ to $3.15 \pm 0.48 \mathrm{~mL} / \mathrm{min}(\mathrm{n}=9 ; P<0.005)$. After $90 \mathrm{~min}$, MBF slowly declined in all 3 nutritional states, but the relative differences were maintained.

\section{Glucose Supply and Uptake by Mammary Tissue}

The results of measurements taken to determine glucose uptake by the inguinal mammary glands of lactating rats are shown in Table 1. Arterial plasma glucose concentration was higher in the refed rats $(8.2$ $\pm 0.2 \mathrm{mM})$ than in both fed and starved rats $(6.6 \pm$ 0.2 and $6.0 \pm 0.1 \mathrm{mM}$, respectively; $P<0.001)$. Overnight starvation decreased glucose AVD by $72 \%(P<$ 0.001). In refed rats, glucose AVD increased to more than twice that of fed rats $(4.2 \pm 0.5$ vs. $1.8 \pm 0.2 \mathrm{mM}$; $P<0.001)$. Statistical analysis using a linear mixed ef-

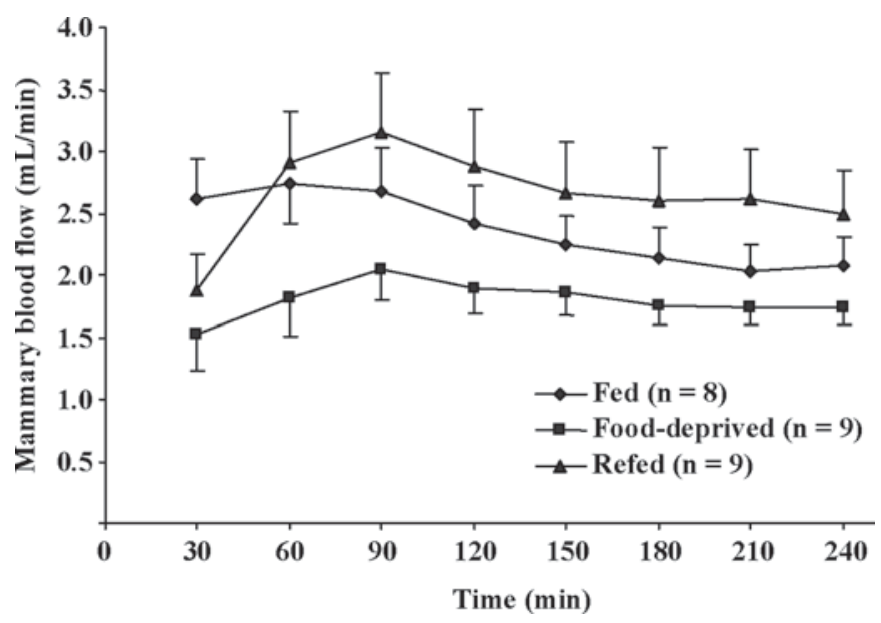

Figure 1. Mean mammary blood flow (MBF) over $4 \mathrm{~h}$ after anesthetization in fed, food-deprived and refed rats (mean \pm SEM). 
Table 1. Effect of nutritional state on glucose supply and uptake by mammary glands ${ }^{1}$

\begin{tabular}{|c|c|c|c|c|c|c|c|c|}
\hline State & $\begin{array}{c}\text { Arterial } \\
\text { [glucose] } \\
(\mathrm{m} M)\end{array}$ & $\begin{array}{c}\text { Mammary } \\
\text { venous } \\
\text { [glucose] }(\mathrm{m} M)\end{array}$ & $\begin{array}{l}\text { Glucose } \\
\text { AVD }^{2} \\
(\mathrm{~m} M)\end{array}$ & $\begin{array}{c}\text { Hematocrit } \\
(\%)\end{array}$ & $\mathrm{MBF}^{3}$ & $\begin{array}{c}\text { Glucose } \\
\text { supply } \\
(\mu \mathrm{mol} / \mathrm{min})\end{array}$ & $\begin{array}{c}\text { Glucose } \\
\text { uptake } \\
(\mu \mathrm{mol} / \mathrm{min})\end{array}$ & $\begin{array}{c}\text { Glucose } \\
\text { extracted } \\
(\%)\end{array}$ \\
\hline Fed & $6.6 \pm 0.2^{\mathrm{b}}$ & $4.7 \pm 0.4$ & $1.8 \pm 0.2^{\mathrm{b}}$ & $41.2 \pm 0.4^{\mathrm{b}}$ & $3.1 \pm 0.2^{\mathrm{a}}$ & $11.8 \pm 0.6^{\mathrm{a}}$ & $3.3 \pm 0.4^{\mathrm{ab}}$ & $28.3 \pm 4.0^{\mathrm{h}}$ \\
\hline Refed & $8.2 \pm 0.2^{\mathrm{a}}$ & $4.3 \pm 0.5$ & $4.2 \pm 0.5^{\mathrm{a}}$ & $47.1 \pm 0.6^{\mathrm{a}}$ & $2.0 \pm 0.3^{\mathrm{b}}$ & $8.8 \pm 1.3^{\mathrm{ab}}$ & $3.9 \pm 0.4^{\mathrm{a}}$ & $49.0 \pm 5.9^{\mathrm{a}}$ \\
\hline
\end{tabular}

${ }^{\mathrm{a}-\mathrm{c}}$ Means within a column with different superscripts differ (1-way ANOVA, $P<0.05$ ).

${ }^{1}$ Results are expressed as mean \pm standard error of the mean (SEM).

${ }^{2} \mathrm{AVD}=$ arterio-venous difference.

${ }^{3} \mathrm{MBF}=$ mammary blood flow.

fects model (iterative generalized least squares fitted by REML, S-PLUS) showed that there were no significant interaction effects of nutritional state, MBF, hematocrit, blood glucose concentration, maternal weight, or litter size on glucose AVD ( $P>0.05$ in all cases).

Blood flow to the left inguinal mammary glands decreased from $3.1 \pm 0.2$ to $1.5 \pm 0.2 \mathrm{~mL} / \mathrm{min}$ in starved rats $(P<0.001)$. In rats that had been refed, MBF was $2.0 \pm 0.3 \mathrm{~mL} / \mathrm{min}$. This was still lower than MBF in fed rats $(P<0.01)$. Hematocrit increased from $41.2 \pm 0.4 \%$ to $47.7 \pm 0.5 \%$ with starvation $(P<0.001)$ and was not significantly changed by refeeding $(47.1 \pm 0.6 \%)$.

The rate of glucose uptake by the left inguinal mammary tissue was calculated. Glucose uptake decreased $88 \%$, from $3.3 \pm 0.4 \mu \mathrm{mol} / \mathrm{min}$ in fed rats to $0.4 \pm 0.1$ $(\mathrm{n}=7 ; P<0.001)$ with overnight food withdrawal and was fully restored to the level in fed rats after refeeding $(3.9 \pm 0.4)$ in spite of the fact that MBF had not yet returned to the fed level $(2.0 \pm 0.3 \mathrm{~mL} / \mathrm{min} ; P<0.01)$. In fed rats, $28.3 \%$ of the glucose entering an inguinal mammary gland was removed. Starvation resulted in a $60 \%$ decrease in glucose supply and a $70 \%$ decrease in the percentage of glucose extracted by the gland. After refeeding, the amount of glucose supplied to the gland had returned to a level that was not significantly less than that in fed rats $(P=0.071)$, but glucose extraction increased to a level $73 \%$ higher than that in fed rats.

The average weight of the inguinal mammary tissue was $6.8 \pm 0.2 \mathrm{~g}(\mathrm{n}=28)$. It has previously been determined that the superficial epigastric artery perfused approximately $80 \%$ of the inguinal mammary tissue (Calvert and Clegg, 1996). Using this figure, mammary glucose uptake in the fed rats in this experiment was estimated to be $0.61 \mu \mathrm{mol} / \mathrm{min}$ per gram of wet mammary tissue.

\section{Effects of Section of the Mammary Nerve}

Section of the nerve supplying the inguinal mammary glands of lactating rats had immediate, hemodynamic effects in most rats. In general, mean arterial blood pressure (MAP) decreased before returning and stabilizing at close to the pre-severance level over a period of up to $3 \mathrm{~min}$. Mammary blood flow sometimes increased for a few seconds after section of either the ipsilateral or contralateral nerves but then decreased by amounts ranging from $10 \%$ to $70 \%$ before returning and stabilizing at near the pre-severance level over a period of up to $9 \mathrm{~min}$.

In Table 2 the mean of 3 control measurements with the mammary nerve intact is compared with the pooled mean of measurements 10- and 20-min post-section on parameters enabling calculation of glucose uptake, and on MAP in food-deprived, normally fed, and refed rats $(\mathrm{n}=7$, except for MAP in fed and refed rats where $\mathrm{n}=$ 3 ; the 10- and 20-min post-section results were pooled as there were no statistical differences between the 2 groups).

Section of the mammary nerve in food-deprived lactating rats resulted in a further decrease in glucose AVD and glucose uptake by the inguinal mammary glands supplied by that nerve $(P=0.03)$. Mammary blood flow was not changed but MAP was significantly decreased by denervation in food-deprived $\operatorname{rats}(P=$ 0.001). In fed and refed rats, denervation decreased MBF by $9 \%(P=0.04)$ and $22 \%(P=0.01)$ respectively. Mammary venous glucose concentration fell by $16 \%$ in refed rats $(P=0.005)$.

Section of the contralateral mammary nerve in fed and refed rats produced similar results. Mammary blood flow was not reduced, but MAP decreased (from $108 \pm 2$ to $102 \pm 3 \mathrm{mmHg} ; P=0.005, \mathrm{n}=6$; 3 fed and 3 refed rats). This indicates that the decrease in MBF that occurred with ipsilateral denervation in fed and refed rats is likely due to removal of neural connections to the gland and not to systemic hemodynamic changes.

\section{Immediate Effects of Insulin and Gut Extract}

Administration of $0.2 \mu \mathrm{g}$ of insulin i.v. had no discernable immediate effect on MBF and MAP $(n=5)$. Intraperitoneal administration of gut extract had a 
Table 2. Effect of section of the mammary nerve in lactating rats in different nutritional states ${ }^{1}$

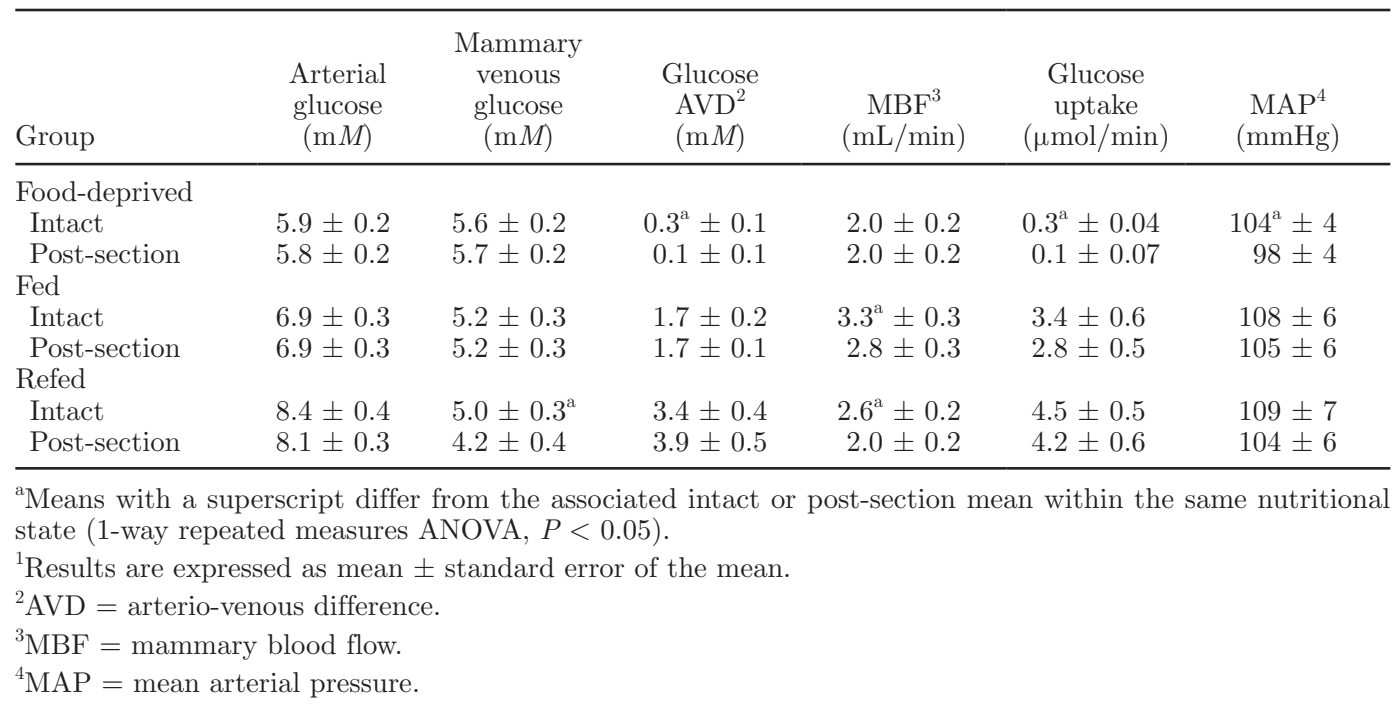

dramatic effect on MBF and MAP. Although the time course of responses varied, in all cases there was a rapid and substantial increase in MAP (average 21\%) for several minutes before slowly declining $(\mathrm{n}=11)$. After an initial increase, MBF tended to decrease to below baseline before slowly recovering.

\section{Effects of Insulin and Gut Extract in Lactating Rats with Ipsilateral Gland Denervation}

The effects of administration of insulin or insulin plus gut extract on arterial plasma glucose concentration, mammary glucose extraction, MBF, glucose uptake, and MAP over $20 \mathrm{~min}$ in lactating rats, 20 min after ipsilateral gland denervation are shown in Figure 2.

The intravenous administration of $0.2 \mu \mathrm{g}$ of insulin in food-deprived lactating rats resulted in a $9.3 \%$ decline in arterial plasma glucose concentration. This reached statistical significance at $15 \mathrm{~min}(P=0.045)$. Addition of gut extract reversed this decline and arterial plasma glucose concentration was increased at 10 and $15 \mathrm{~min}$, before declining after $20 \mathrm{~min}$. In spite of this increase, mammary venous glucose concentration did not increase (data not shown); consequently, glucose extraction was temporarily increased almost 4-fold after $10 \mathrm{~min}$ (from $3.4 \pm 1.3$ to $13.0 \pm 1.8 \% ; P<0.001, \mathrm{n}=7$ ). However, this did not reflect increased mammary glucose uptake, as the glucose supply to the glands had decreased because of a decrease in MBF. The decrease in MBF in response to gut extract administration occurred in association with a sustained elevation in blood pressure. Mean arterial blood pressure increased rapidly by $21 \%$ from $95 \pm 1.4$ to $115 \pm 1.4 \mathrm{mmHg}(P<0.001)$ and was maintained at this level over the next $10 \mathrm{~min}$.

\section{DG Uptake by Mammary Acini}

The uptake of ${ }^{3} \mathrm{H}-2 \mathrm{DG}$ by acini from fed lactating rats over a 1-h incubation was calculated to be $0.36 \pm$ $0.06 \mu \mathrm{mol} / \mathrm{min}$ per gram. Uptake in acini from fooddeprived rats was $35 \%$ less $(P=0.034)$.

\section{Effect of Insulin and Gut Extract on 2DG Uptake in Acini from Fed and Food-Deprived Rats}

Administration of insulin at approximately 100 times the physiological concentration increased 2DG uptake by acini from both fed and food-deprived rats by 46 and $55 \%$, respectively $(\mathrm{n}=7)$. Similarly, administration of insulin at 1,000 times the physiological concentration, the respective increase was 58 and $36 \%(\mathrm{n}=6)$.

Administration of a crude gut extract did not increase 2DG uptake in acini from fed rats, but one extract did increase uptake in acini from food-deprived rats by $35 \%$ $(P=0.025)$ and when given with insulin the increase was $83 \%$. However, this effect was not seen with 14 further extract preparations. Extract fractions from which all proteins larger than $10 \mathrm{kDa}$ had been removed did not significantly increase glucose uptake.

\section{DISCUSSION}

A perivascular flow probe was used to provide the first continuous measurements of blood flow to the inguinal mammary glands of anesthetized lactating rats. The method established that MBF is well maintained in anesthetized rats for up to $4 \mathrm{~h}$. Gentle positioning of the flow probe was found to be important because any manipulation of the mammary blood vessels or nerve 

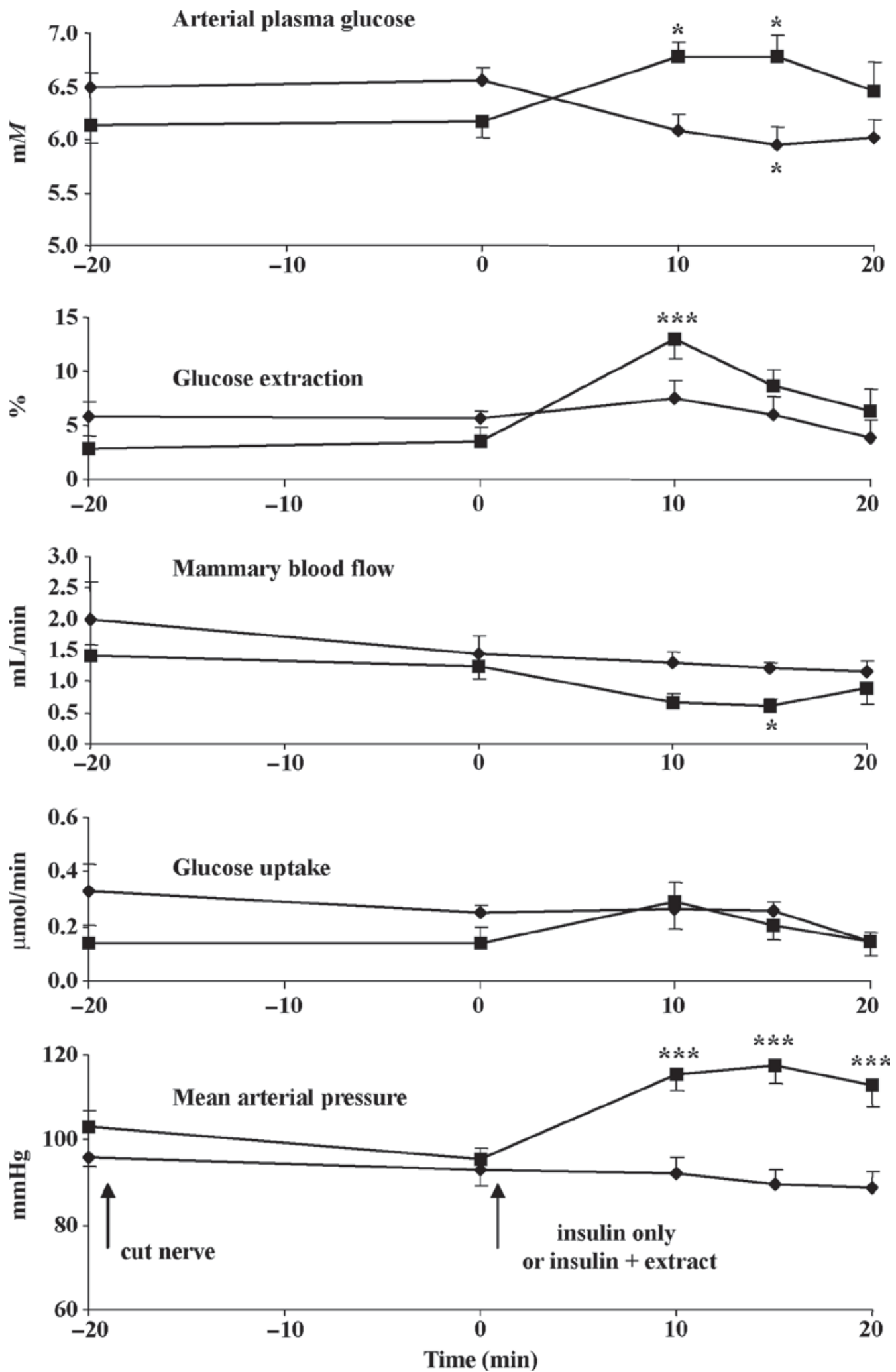

Figure 2. The effect of insulin alone or with gut extract in food-deprived rats. These graphs show the effect of $0.2 \mu \mathrm{g}$ of insulin i.v. $(\bullet ; \mathrm{n}=$ 6) and the effects of $0.2 \mu \mathrm{g}$ of insulin i.v. and $10 \mathrm{mg}$ of gut extract protein i.p. given simultaneously $(\mathbf{\square} ; \mathrm{n}=7)$ on arterial glucose concentration, glucose extraction, mammary blood flow, mammary glucose uptake, and mean arterial pressure, 20 min after cutting the mammary nerve in food-deprived lactating rats. Statistical comparison, using 2-way repeated measures ANOVA, compares data at time 0 with data at times 10 , 15 , and 20 min. ${ }^{*} P<0.05 ; * * P<0.001$. 
resulted in a severe decrease in blood flow, which often took several minutes to recover.

Blood flow in the left inguinal mammary artery of Sprague-Dawley rats at peak lactation, measured 30 min after induction of anesthesia, was $2.6 \mathrm{~mL} / \mathrm{min}$ or approximately $0.48 \mathrm{~mL} / \mathrm{min}$ per gram of mammary tissue (using the assumption that gland weight in rats at peak lactation is about $80 \%$ glandular tissue; Calvert and Clegg, 1996). Previously published indirect estimates of $\mathrm{MBF}$ in rats at peak lactation range from 0.43 to $1.01 \mathrm{~mL} / \mathrm{min}$ per gram (Hanwell and Linzell, 1972, 1973; Jones and Williamson, 1984; Vina et al., 1985).

As expected, MBF was found to decrease substantially with an 18-h food deprivation. For example, in the group of rats used to measure glucose uptake, MBF decreased by $52 \%$. Previous studies that assessed MBF by the distribution of radiolabeled microspheres reported a decrease in MBF in food-deprived lactating rats of $25 \%$ (Vina et al., 1985) and $45 \%$ (Jones and Williamson, 1984) after $6 \mathrm{~h}$, and $53 \%$ after $24 \mathrm{~h}$ of food deprivation (Vina et al., 1985; Page and Kuhn, 1986). Thus, the indirect methods for measuring MBF gave an accurate indication of the size of the decrease in MBF occurring when the animals are deprived of food.

Few studies have examined the effect of refeeding food-deprived mammals on MBF. In the only study reported in lactating rats, MBF increased with refeeding after $6 \mathrm{~h}$ of food deprivation from $45 \%$ lower than the fed level to $37 \%$ lower than the fed level after $2 \mathrm{~h}$ (Jones and Williamson, 1984). In the present study, refeeding of food-deprived rats before anesthesia was shown to completely restore $\mathrm{MBF}$ to the pre-food deprivation flow rate 2 to $2.5 \mathrm{~h}$ after reoffering food.

The blood sampling technique developed in this study enabled the withdrawal of blood without altering MBF, which was recorded throughout the process. Mammary blood flow was found to be very sensitive to any disturbance. If the mammary blood vessels were inadvertently touched or manipulated, MBF decreased immediately and remained low for varying periods in proportion to the degree of disruption for up to 10 min. It is clear from observation of the continuous record of MBF that methods involving puncture of the mammary vein used by previous researchers to obtain mammary venous blood would have severely decreased $\mathrm{MBF}$ and thus affected glandular metabolism. The criterion of steady-state blood flow required for accurate AVD measurement (Zierler, 1961) would not be met, and therefore, the results of previous AVD measurements and the conclusions derived from them must be assumed to be of questionable accuracy.

Mean glucose extraction from the steady-state flow of blood supplying the lactating mammary tissue of the normally fed rats in this study was $28 \%$. In spite of the potential limitations in the methods used by other researchers, in 3 cases, the results were similar to those of the present study: 25\% (Hawkins and Williamson, 1972), 30\% (Robinson and Williamson, 1977a), and 35\% (Jones and Williamson, 1984). In one case, however, serial sampling at 5-min intervals consistently measured glucose extraction at approximately 60\% (Page and Kuhn, 1986). This is clearly higher than normal and, given that mammary venous blood was obtained by puncture of the mammary vein, is probably explained by a decrease in MBF.

Another factor that could have contributed to the varied results in previous studies is contamination of the venous sample produced by the sampling method. When the vein is punctured, the rapid outflow of blood is likely to include blood flowing back from the femoral vein, thus contaminating the sample with nonmammary venous blood. The slow withdrawal of blood from the catheter positioned at the exit of the mammary vein in the present study was conducted to prevent contamination.

The calculated mean uptake of glucose in the present study was $0.61 \mu \mathrm{mol} / \mathrm{min}$ per gram of wet mammary tissue. A previous estimate from single measurements of the distribution of radiolabeled microspheres was $1.47 \mu \mathrm{mol} / \mathrm{min}$ per gram (Jones and Williamson, 1984). As the measurement for glucose extraction was similar to the result in the present study (35\% compared with $28 \%$ ), the higher glucose uptake result obtained by Jones and Williamson (1984) is probably explained by overestimation of MBF.

After overnight food deprivation, the glucose supply decreased by $60 \%$ but mean uptake by the glands fell to only $8 \%$ of the uptake in fed animals. This decrease in uptake cannot be attributed simply to a decrease in blood flow or in arterial glucose concentration. Clearly, the metabolic demand for glucose is decreased by mechanisms other than substrate availability. Although, to our knowledge, this is the first time mammary glucose uptake has been determined using simultaneous measurements of glucose extraction and MBF in rats, the decrease in glucose uptake with food deprivation is in line with expectations from experiments that have measured these parameters separately.

After $1 \mathrm{~h}$ of refeeding, glucose extraction rose to a level much higher than in fed rats (49\% of the glucose entering the gland, a level $73 \%$ higher than in the fed rats). This was in spite of the fact that the supply of glucose to the gland was similar to that of fed rats. This demonstrates that glucose uptake by mammary tissue was not well correlated with the supply of glucose. The results of this study add weight to the suggestion of other researchers (Jones and Williamson, 1984; Mercer and Williamson, 1987; Hagopian and Munday, 1997) 
that mammary gland metabolism is not merely dictated by substrate supply to the gland, but is able to adjust its metabolism in response to substrate availability. The signaling pathways for these changes are unclear, but they are rapid and, in the case of refeeding, the restoration in glucose uptake precedes the restoration in MBF and presumably, the absorption of appreciable quantities of nutrients from the gastrointestinal tract.

In these experiments, mean hematocrit increased $17 \%$ with overnight food deprivation. This does not appear to have been reported before in rats, but is consistent with the prior observation that a 48 -h food deprivation did result in a $9 \%$ increase in hematocrit in lactating goats (Chaiyabutr et al., 1980). It is also consistent with the previously documented observation of decreased plasma volume with food deprivation in rats despite ad libitum access to water (Lasher et al., 1958; Wright and O'Kelly, 1973).

The mechanism by which food deprivation results in reduced plasma volume is not clear. However, negative water balance associated with short-term food deprivation in the present study and studies in goats (Chaiyabutr et al., 1980) and rats (Amlal et al., 2001) was not accompanied by plasma hyperosmolality. A reduction in blood volume without causing plasma hyperosmolality can only be explained by the movement of isotonic fluid from the vascular compartment to the interstitial and intracellular body fluid compartments (Ware et al., 1982).

This may explain why the rats did not replenish their plasma volume by increasing their water intake. The thirst mechanism in mammals appears to be more responsive to plasma osmolality than a decrease in extracellular fluid volume (Antunes-Rodrigues et al., 2004). Another possible factor is that lactating rats appear to be less responsive to dipsogenic stimuli arising from deficits in both their intracellular and extracellular fluid spaces than nonlactating rats (Kaufman, 1981).

This research also addressed the question of whether the food deprivation-induced shutdown in mammary metabolism was due to inhibitory neural pathways. If this was the case, interruption of the nerve supply to the mammary glands may be expected to result in an increase in mammary glucose uptake in food-deprived lactating rats. This was attempted by severing the nerve alongside the mammary artery and vein. This procedure was expected to remove the majority of the innervation of the associated inguinal mammary gland, but it is acknowledged that there may be some remaining sympathetic adrenergic and nonadrenergic, noncholinergic post-ganglionic fibers present in the walls of the mammary blood vessels.

However, rather than increasing glucose uptake, severing of the nerve to the inguinal mammary glands further decreased glucose uptake in food-deprived rats in this study. The time between cutting the nerve and taking glucose uptake measurements (10 and 20 min) was expected to be long enough for any effects of denervation to be evident if they were important in the short-term maintenance of the rate of mammary metabolism. In the absence of guidance from previous studies examining the effect of denervation on mammary glucose uptake, this temporal assessment was based on the observation that refeeding resulted in a $40 \%$ increase in mammary glucose extraction after 15 min in lactating rats, which had been food-deprived for the same length of time as the rats in the current study (Page and Kuhn, 1986).

The converse, that neural stimulation contributed to supporting mammary metabolism in fed and refed rats, was also tested. Sectioning of the ipsilateral nerve did not reduce glucose uptake but did reduce MBF. However, sectioning of the contralateral nerve did not reduce MBF. This provides evidence of neural support for the supply of nutrients to the glands when food is available.

The mechanism by which severing the mammary nerve reduces blood pressure is not clear but a vasodilatory response would be consistent with the transient increase in $\mathrm{MBF}$ that was sometimes coincident with the decrease in pressure immediately after the nerve was cut. The subsequent decrease in MBF could be explained by a baroreceptor-mediated sympathetic response to the lowered systemic pressure, causing release of adrenal catecholamines and consequent constriction of the mammary vasculature. Electrical stimulation of the central end of this nerve has previously been shown to cause the systemic release of catecholamines in lactating rats (Clapp et al., 1985), and cutting of the nerves may produce a burst of impulses that mimics electrical stimulation.

The conclusion from these results is that MBF may be supported by neural pathways when food is available but that maintenance of the rate of mammary metabolism during altered nutritional state is not dependent on the neural pathways within the mammary nerve, at least in the short term. This is consistent with the lack of identified efferent neural pathways to mammary tissue (Findlay and Grosvenor, 1969; Hebb and Linzell, 1970; Vorherr, 1974) and the observation that the reduction in milk secretion and blood flow resulting from starvation in lactating goats was similar in denervated (auto-transplanted) mammary glands (Chaiyabutr et al., 1980).

Nevertheless, Page found that nerve section was necessary to allow physiological levels of insulin to stimulate mammary metabolism in food-deprived rats (Page, 1989). In his experiments, intravenous administration 
of insulin markedly increased mammary glucose extraction in denervated rats. However, these results were not reproduced in the present study. Intravenous administration of the same dose of insulin did not increase glucose AVD or mammary glucose uptake.

To investigate the possibility that a factor from the gut, along with insulin, signals the arrival of food to the mammary glands, a gut extract was prepared following the protocol reported by Page. However, in contrast to an increase in glucose extraction to around $50 \%$ after $10 \mathrm{~min}$ as reported by Page (1989), glucose extraction increased to $13 \%$ before declining to $6 \%$ after $20 \mathrm{~min}$. Mammary glucose uptake also showed a parallel pattern of change but at no time was uptake greater than $10 \%$ of fed levels.

Administration of gut extract also increased MAP by over $20 \%$, making any changes in mammary glucose metabolism difficult to differentiate from the effects of the hemodynamic changes. As Page (1989) did not measure $\mathrm{MBF}$ or blood pressure he could not have known if the extract had a hypertensive action.

To eliminate systemic effects such as hemodynamic changes, an in vitro method was used to examine the uptake of glucose by mammary acini. The rate of glucose uptake was found to be $35 \%$ lower in acini from fooddeprived rats compared with fed rats. This reduction was proportionately less than that observed with food deprivation in vivo (glucose uptake in food-deprived rats was $88 \%$ lower than in fed rats), suggesting that glucose uptake had recovered to some degree in the acini from food-deprived rats. Whether the recovery was due to removal of a substance that was inhibiting metabolism in vivo or provision of a substrate(s) that was deficient in vivo cannot be determined. However, the observation that the acini from food-deprived rats had some residual effect of food deprivation on glucose uptake indicated that there was a metabolic alteration in the mammary cells in food-deprived rats that persisted for at least $2.5 \mathrm{~h}$ after being placed in culture medium. A similar residual effect of food deprivation ( $28 \%$ lower than fed) was seen in a previous experiment using acini from rats deprived of food for $24 \mathrm{~h}$ (Robinson and Williamson, 1977a).

In the study of Robinson and Williamson (1977a), administration of insulin increased glucose uptake in mammary acini from food-deprived rats, but not from fed lactating rats. However, in our experiments glucose transport in acini from fed rats was just as responsive to insulin as those from food-deprived rats using doses of insulin that were 7 and $65 \%$ of that used by Robinson and Williamson (1977a). The fact that there was a similar increase with both doses of insulin in our study presumably indicates that the response to the lower dose was already maximal.
The results from addition of crude gut extract were inconclusive. There were indications that glucose uptake in cells from food-deprived rats may have been increased but the effect was not consistently observed with different extract preparations. This could have been due to limitations in the in vitro method rather than lack of bioactive agents in the extract, as factors such as cell-dispensing variability and loss of cells during processing after incubation prevented the detection of small increases in glucose uptake. Other researchers have reported similar difficulty (Threadgold et al., 1982). The fact that another research group reported increased glucose uptake when a similarly prepared gut extract was administered to murine mammary HC11 cells (Myung and Ahn, 2002) supports the existence of an active factor.

In summary, an accurate method of measuring MBF and a nondisruptive mammary venous blood sampling technique have provided a clearer picture of the effect of changes in nutritional status on mammary blood and substrate supply and the time course of recovery of these parameters after food deprivation in anesthetized lactating rats. The rate of mammary metabolism, as indicated by the uptake of glucose by mammary tissue, bore no relation to the supply of substrate to the glands and so appears unlikely to be a major factor in the control of mammary metabolism. Neural pathways to the gland also appeared to have little influence on mammary metabolism, but insulin stimulated the uptake of glucose by mammary cells and may be an important component in the mammary response to changes in nutritional status. There were indications that a bioactive factor from the gut could also play a role.

\section{ACKNOWLEDGMENTS}

Funding for this work was provided by AgResearch (Hamilton, New Zealand), Waikato Institute of Technology (Hamilton, New Zealand), and the Waikato Medical Research Foundation (Hamilton, New Zealand).

\section{REFERENCES}

Amlal, H., Q. Chen, K. Habo, Z. Wang, and M. Soleimani. 2001. Fasting downregulates renal water channel AQP2 and causes polyuria. Am. J. Physiol. Renal Physiol. 280:F513-F523.

Antunes-Rodrigues, J., M. de Castro, L. L. Elias, M. M. Valenca, and S. M. McCann. 2004. Neuroendocrine control of body fluid metabolism. Physiol. Rev. 84:169-208.

Bussmann, L. E., S. Ward, and N. J. Kuhn. 1984. Lactose and fatty acid synthesis in lactating-rat mammary gland. Effects of starvation, refeeding, and administration of insulin, adrenaline, streptozotocin and 2-bromo-alpha-ergocryptine. Biochem. J. 219:173-180.

Calvert, D. T., and R. A. Clegg. 1996. Responses of glucose metabolism to insulin in perfused mammary tissue of lactating rats: Influence of dietary history and recent insulin experience. Exp. Physiol. $81: 131-140$. 
Carrick, D. T., and N. J. Kuhn. 1978. Diurnal variation and response to food withdrawal on lactose synthesis in lactating rats. Biochem. J. 174:319-325.

Chaiyabutr, N., A. Faulkner, and M. Peaker. 1980. Effects of starvation on the cardiovascular system, water balance and mild secretion in lactating goats. Res. Vet. Sci. 28:291-295.

Chatwin, A. L., J. L. Linzell, and B. P. Setchell. 1969. Cardiovascular changes during lactation in the rat. J. Endocrinol. 44:247-254.

Clapp, C., G. Martinez-Escalera, M. T. Morales, S. W. Shyr, C. E. Grosvenor, and F. Mena. 1985. Release of catecholamines follows suckling or electrical stimulation of mammary nerve in lactating rats. Endocrinology 117:2498-2504.

Clegg, R. A. 1988. Regulation of fatty acid uptake and synthesis in mammary and adipose tissues: contrasting roles for cyclic AMP. Curr. Top. Cell. Regul. 29:77-128.

Diehl, K. H., R. Hull, D. Morton, R. Pfister, Y. Rabemampianina, D. Smith, J. M. Vidal, and C. van de Vorstenbosch. 2001. A good practice guide to the administration of substances and removal of blood, including routes and volumes. J. Appl. Toxicol. 21:15-23.

Faulkner, A., and M. Peaker. 1987. Regulation of Mammary Glucose Metabolism in Lactation. Plenum Press, New York, NY.

Findlay, A. L. R., and C. E. Grosvenor. 1969. The role of mammary gland innervation in the control of the motor apparatus of the mammary gland. Dairy Sci. Abstr. 31:109-116.

Hagopian, K., and M. R. Munday. 1997. The role of pyruvate dehydrogenase, phosphofructo-1-kinase and acetyl-CoA carboxylase in the regulation of fatty acid synthesis in the lactating rat mammary gland during the starved to refed transition. Biochim. Biophys. Acta 1336:474-484.

Hanwell, A., and J. L. Linzell. 1972. Determination of cardiac output and mammary blood flow in the conscious lactating rat. J. Physiol. 226:24P-25P.

Hanwell, A., and J. L. Linzell. 1973. The effects of engorgement with milk and of suckling on mammary blood flow in the rat. J. Physiol. 233:111-125.

Hawkins, R. A., and D. H. Williamson. 1972. Measurements of substrate uptake by mammary gland of the rat. Biochem. J. 129:1171-1173.

Hebb, C., and J. L. Linzell. 1970. Innervation of the mammary gland. A histochemical study in the rabbit. Histochem. J. 2:491-505.

Jones, R. G., V. Ilic, and D. H. Williamson. 1984. Regulation of lactating-rat mammary-gland lipogenesis by insulin and glucagon in vivo. The role and site of action of insulin in the transition to the starved state. Biochem. J. 223:345-351.

Jones, R. G., and D. H. Williamson. 1984. Alterations in mammarygland blood flow and glucose metabolism in the lactating rat induced by short-term starvation and refeeding. Biosci. Rep. 4:421-426.

Katz, J., P. A. Wals, and R. L. Van de Velde. 1974. Lipogenesis by acini from mammary gland of lactating rats. J. Biol. Chem. 249:7348-7357.

Kaufman, S. 1981. Control of fluid intake in pregnant and lactating rats. J. Physiol. 318:9-16.

Lasher, E. P., B. S. Simmons, and N. B. Everett. 1958. Effects of semistarvation on the distribution of erythrocytes and plasma in organs and tissues of the rat. J. Nutr. 65:317-326.

Mendelson, C. R., and R. O. Scow. 1972. Uptake of chylomicron triglyceride by perfused mammary tissue of lactating rats. Am. J. Physiol. 223:1418-1423.

Mercer, S. W., and D. H. Williamson. 1986. Time course of changes in plasma glucose and insulin concentrations and mammary gland lipogenesis during refeeding of starved conscious lactating rats. Biochem. J. 239:489-492.
Mercer, S. W., and D. H. Williamson. 1987. The regulation of lipogenesis in vivo in the lactating mammary gland of the rat in the starved-refed transition. Studies wtih acarbose, a glucosidase inhibitor. Biochem. J. 242:235-243.

Myung, K. H., and B. J. Ahn. 2002. Effects of gut extract protein and insulin on glucose uptake and GLUT1 expression in HC11 mouse mammary epithelial cells. Asian-australas. J. Anim Sci. $15: 1210-1214$

Page, T. 1989. Evidence for the involvement of a gastrointestinal peptide in the regulation of glucose uptake in the mammary gland of the lactating rat. Biochem. J. 258:639-643.

Page, T., and N. J. Kuhn. 1986. Arteriovenous glucose differences across the mammary gland of the fed, starved, and re-fed lactating rat. Biochem. J. 239:269-274.

Robinson, A. M., and D. H. Williamson. 1977a. Comparison of glucose metabolism in the lactating mammary gland of the rat in vivo and in vitro. Biochem. J. 164:153-159.

Robinson, A. M., and D. H. Williamson. 1977b. Effects of acetoacetate administration on glucose metabolism in mammary gland of fed lactating rats. Biochem. J. 164:749-752.

Threadgold, L. C., H. G. Coore, and N. J. Kuhn. 1982. Monosaccharide transport into lactating rat mammary acini. Biochem. J. 204:493501

Threadgold, L. C., and N. J. Kuhn. 1984. Monosaccharide transport in the mammary gland of the intact lactating rat. Biochem. J. 218:213-219

Vina, J. R., A. Rodriguez, J. B. Montoro, A. Iradi, and I. R. Puertes, and J. Vina. 1985. Blood flow and net amino acid uptake by the lactating mammary gland: Effect of starvation. Biochem. Soc. Trans. 13:876-877.

Vina, J. R., I. R. Puertes, J. B. Montoro, and J. Vina. 1983. Effect of starvation and re-feeding on amino acid uptake by mammary gland of the lactating rat. Role of ketone bodies. Biochem. J. 216:343-347.

Vina, J. R., I. R. Puertes, A. Rodriguez, G. T. Saez, and J. Vina. 1987. Effect of fasting on amino acid metabolism by lactating mammary gland: Studies in women and rats. J. Nutr. 117:533-538.

Vina, J. R., I. R. Puertes, and J. Vina. 1981. Effect of premature weaning on amino acid uptake by the mammary gland of lactating rats. Biochem. J. 200:705-708.

Vorherr, H. 1974. Mammary innervation. Pages 34-41 in The Breast: Morphology, physiology and lactation. H. Vorherr, ed. Academic Press Inc., New York, NY.

Ware, J., K. A. Norberg, M. Norman, and G. Nylander. 1982. ${ }^{51} \mathrm{Cr}$ EDTA determinations of the extracellular fluid volume in hemorrhage: A study with fed and starved rats. Acta Physiol. Scand. 116:235-238.

Williamson, D. H. 1980. Integration of metabolism in tissues of the lactating rat. FEBS Lett. 117(Suppl.):K93-K105.

Williamson, D. H., and A. M. Robinson. 1977. Control of glucose metabolism in lactating-rat mammary gland: Effects of other substrates, insulin and starvation . Biochem. Soc. Trans. 5:829834

Wright, J. W., and L. I. O'Kelly. 1973. Deviations in body fluids during fasting in rats: Failure of $\mathrm{ADH}$ treatment and nonnutritive bulk in preventing the occurrence of plasma hypovolemia. Physiol. Behav. 11:791-800.

Zierler, K. L. 1961. Theory of the use of arteriovenous concentration differences for measuring metabolism in steady and non-steady states. J. Clin. Invest. 40:2111-2125. 